\title{
DESAFIOS NA PESQUISA EM SEGURANÇA DO PACIENTE
}

\author{
Elaine Drehmer de Almeida Cruz ${ }^{1}$
}

\begin{abstract}
A Revista Cogitare Enfermagem elegeu Segurança do Paciente como tema central da edição especial comemorativa aos 20 anos de publicação.Esta publicação agrega-se à pesquisas epidemiológicas sobre ocorrências não desejadas durante a assistência em saúde, as quais tem destaque nos últimos anos. Diante da dura realidade observada no cotidiano do cuidado, diferentes enfrentamentos compõem as políticas públicas e institucionais, as quais colaboram para aprofundar o conhecimento da magnitude do problema e estruturar estratégias de prevenção e controle desses agravos à saúde.

Inegável é a relevância das iniciativas da Organização Mundial da Saúde e de Agências reguladoras da qualidade e segurança assistencial, e seu impacto ao estabelecer padrões de excelência. Parte das ações ora estabelecidas nas políticas públicas é reconhecida há décadas como evidência para a prevenção de agravos. Como exemplos, cuidados elementares para a prevenção, entre outros, de úlceras por pressão, quedas, erros de medicação e infecções relacionadas à assistência. Ora, se básicos e reconhecidos como irrefutáveis, a exemplo de mudança de decúbito, manutenção de grades da cama elevadas, conferência da droga prescrita, preparada e administrada, e higiene de mãos, o porquê a adesão dos profissionais de enfermagem é tão baixa a esses preceitos?As pesquisas observacionais revelam parcialmente a realidade, e ouso dizer que o muito apresentado mostraapenas parte do contexto assistencial; a realidade é muito pior.Irrefutável é a necessidade do aprofundamento e ampliação das investigações para melhor compreensão dos determinantes da baixa adesão às ações básicas, mas fundamentais à segurança do paciente.
\end{abstract}

Frente à magnitude da diversidade e a complexidade que compõe a relação de cuidado, reflito sobre potenciais objetos de pesquisa que considero fundamentais para a Enfermagem neste enfrentamento: o conhecimento científico, o contexto assistencial e o comportamento humano.

Formação universitária e força de trabalho de enfermagem são evidências demonstradas, por estudiosos, em prol da segurança do paciente em diferentes países desenvolvidos. No Brasil, a pesquisa Perfil da Enfermagem revelou, recentemente, que apenas $20 \%$ da força de trabalho é composta por enfermeiros e que $66 \%$ dos participantes apontam desgaste profissional. Inegável é a importância desses aspectos na realização do cuidado seguro; a formação e qualificação profissional e a relação enfermagem-paciente devem ser considerados no bojo das políticas públicas e institucionais ao se pretender a segurança. Deste modo, é importante demonstrar, também no contexto nacional, evidencias que suportem a luta por mudanças que corroborem para a qualidade da assistência e amparem novos dispositivos legais da profissão.

Associado aos fatores agravantes baixa qualificação e alta relação enfermagem-paciente está o comportamento humano; a esse agregado está o valor atribuído pelo profissional ao paciente e às ações básicas de segurança. Possivelmente nem sempre é a sobrecarga ou o desconhecimento que desencadeiam incidentes em saúde, mas o descaso e o sentimento de impunidade frente ao cuidado inseguro, deliberadamente, praticado.Atos inseguros e que resultam em erros de omissão - não fazer o correto - constituemoutro grande desafio à segurança do paciente, pois frequentemente compõem, de forma quase natural, a prática em saúde.

${ }^{1}$ Professora do Curso de Graduação e Pós-Graduação em Enfermagem da Universidade Federal do Paraná. Membro do Grupo Multiprofissional em Saúde do Ádulto na temática Segurança do Paciente. 
Resultados de pesquisas podem direcionar as estratégias, certamente diversas, para alcançar e manter a almejada qualidade da assistência, esta atrelada à segurança e personificada no cuidado planejado, executado por força de trabalho suficiente e qualificada. Força de trabalho cuja atitude cotidiana tenha o paciente como centro da atenção, elemento fundamental e principal sentido do fazer Enfermagem.

Deste modo considero que os pesquisadores do tema dispõem de amplo material para investigação, a ser realizada preferencialmente de forma multicêntrica, e que agregue evidência científica fundamental ao necessário aprimoramento da prática assistencial de enfermagem. 